\title{
Biotech firms jump on SARS bandwagon
}

Undeterred by the scarcity of clinical data on severe acute respiratory syndrome (SARS), several biotechnology and diagnostics firms are joining the global rush to combat the infectious disease. Hefty government backing and a focus on generating short-term revenue have galvanized companies to switch some of their focus to SARS, despite there being no established market for SARS-related products.

SARS presents an opportunistic scenario similar to the early days of the AIDS epidemic when many biotech companies rushed to refocus efforts towards combating HIV, says Michael Hildreth, the Biotechnology Director of Ernst \& Young Americas (Palo Alto, CA, USA). But geopolitical uncertainties like the recent war in Iraq drive investors to favor companies that can generate profits quickly, says Hildreth. Although SARS market data are scant, experts say the disease can deliver profits in the short term due to the immediate need for a treatment. The SARS virus may also reemerge during the annual flu season in the fall, predict scientists, increasing prospects for a profitable market.

The first companies to jump on the antiSARS bandwagon have been those that are already developing similar technologies for other indications. For example, Roche Diagnostics (Basel, Switzerland) is collaborating with the Genome Institute (Singapore) to codevelop a PCR-based SARS detection kit by the end of July. "We have the knowledge, the instruments, the technology and the money, so we have a duty to create the test," said Baschi Duerr, a spokesman for Roche Diagnostics.

Other firms such as Hemispherx (Philadelphia, PA, USA) are looking for therapeutic opportunities: the company's immunotherapeutic drug Ampligen has recently been found to have high antiviral activity against the SARS virus. Vaccine company GenVec (Gaithersburg, MD, USA) is looking to insert synthetic genetic partial sequences of the SARS coronavirus into a benign adenovirus to produce a new vaccine-a technology they are already using to develop an HIV vaccine.

"Maybe there will be a market, maybe there will be revenue, but it's too early to predict exactly what the market size will be," says Duerr. Aaron Davidson, vice president of the private Canadian venture capital firm Ventures West (Toronto, ON, Canada), believes that the SARS market may be only in vaccines or diagnostics. But investors deem vaccines generally risky, whereas major players in diagnostics like Roche and Abbott Laboratories (Abbott Park, IL, USA) are most likely best positioned to accrue the majority of profits from a SARS diagnostic test.

Although SARS market data are scant, experts say the disease can deliver profits in the short term due to the immediate need for a treatment.

Availability of government funding also attracts companies to SARS. The Chinese government will spend $\$ 6$ million this year combating SARS, say analysts. New Zealand recently offered more than $\$ 1$ million to hard-hit China's anti-SARS efforts and to boost international collaborations in SARS research; similarly, Health Canada allocated $\$ 500,000$ for research against SARS. And several companies like Biota Holdings (Victoria, Australia) are working with US authorities to investigate possible ways to participate in government-funded research programs to combat SARS.
Biotech companies are also forging collaborations with well-funded academic laboratories. Tyson Bioresearch (Hsin-Chu, Taiwan) and the National Taiwan University College of Medicine (Taipei, Taiwan) for example, jointly developed a \$15 SARS diagnostic test that can identify patients affected by the disease 21 days after the onset of symptoms.

Companies are further planning to cash in through potential licensing revenues, a trend reflected by the flurry of SARSrelated patent applications in recent months. For example, Combimatrix (Mukilteo, WA, USA) filed patent applications on 60 antisense drugs against SARS. And Plexus Vaccine (San Diego, CA, USA)_acquired on May 15 by infectious disease firm Siga Technologies (New York, NY, USA)—filed a patent in Denmark covering a new method of analyzing SARS genetic variants.

Eventually, Carter predicts that only a small number of companies will commit resources and develop new products for clinical trials, but this may be years away. But for now, the SARS outbreak has aroused investors' interest in emerging infectious diseases as a whole, says Davidson. Specifically, he predicts that antivirals are likely to attract more investment in the future.

Paroma Basu, New York, NY, USA

\section{US academia held accountable for GM products}

The US Food and Drug Administration (FDA; Rockville, MD, USA) sent a letter dated May 13 to all land grant universities, which do the majority of livestock research, as a reminder notice that any genetically modified (GM) animals destined for human consumption must be reported to the FDA and disposed of properly. The letter reveals federal regulatory agencies' difficulties in keeping track of the next generation of GM research that falls under their jurisdiction. The FDA is therefore shifting the responsibility of regulating GM plant and animal development to universities and researchers, who may be unaware of their new obligations.

The FDA's letter was in response to the selling of GM pigs' non-GM offspring into the food supply by the University of Illinois (UI; Urbana-Champaign, IL, USA) (Nat. Biotechnol. 21, 219, 2003). Bill Murphy, associate chancellor for public affairs at UI, says the university and the FDA were not on the same page concerning the handling of the piglets. He says the new scientific territory for both parties caused the regulatory breakdown: "There's a learning curve on both sides and there's going to be a little bit of a shakeout here."

Murphy noted that two important miscommunications were not highlighted in the FDA letter. The FDA defines investigational animal' (around which the problem arose) as any animal involved in a GM study; and the FDA considers the university, 